\title{
On the Locomotory Rhythm of Brachyuran Crab Larvae and Its Significance in Vertical Migration*
}

\author{
S. D. Sulkin, I. Phillips ${ }^{* *}$ and W. van Heukelem \\ Horn Point Environmental Laboratories, Box 775, Cambridge, Maryland 21613, USA
}

\begin{abstract}
The presence of a locomotory rhythm in the hatching stage of the crab Callinectes sapidus Rathbun was investigated. Larvae were subjected to $12: 12$ light : dark (LD) regimes for the first $48 \mathrm{~h}$ after hatching, then separated into groups held on the 12:12 LD regime or held in constant light (LL). Swimming speeds were measured at $6 \mathrm{~h}$ intervals for larvae in the two groups. In larvae maintained in LD regime, a peak swim speed was measured at successive 0200 readings with reduction in swim speed by the following reading at 0800 . Larvae held in LL showed no such pattern. Continuous LD entrainment is necessary to maintain the rhythm. The rhythm may serve either as a depth regulatory device or as a mechanism for diurnal vertical migration.
\end{abstract}

\section{INTRODUCTION}

The direction and rate of horizontal movement of planktonic animals is often determined by their vertical position in the water column. Thus vertical distribution is an important factor in determining retention within or recruitment to estuarine habitats in benthic species with pelagic larvae (Carriker, 1951; Bousfield, 1955; Thorson, 1964; Wood and Hargis, 1971; Sulkin, 1973, 1975a). The vertical position of a particular larval stage is the result of a complex combination of behavioral responses, involving both direction and rate of movement, as well as such physical parameters as size and shape. Periodic variations in behavioral response could have substantial impact upon vertical distribution and thus influence direction and extent of dispersal.

Periodicity in locomotory response has been documented for many marine invertebrates, including zooplankters (e.g. Naylor, 1958, 1963; Williams and Naylor, 1967, 1969; Enright and Hamner, 1967; Naylor and Williams, 1968; Hughes, 1969a, b, 1972; Fincham, 1970 ; Jones and Naylor, 1970; Allen, 1972; Honegger, 1973; Hindley, 1974; Cronin and Forward, 1979; for a pertinent review consult 'Marine Ecology', Volume II: Enright, 1975).

The present experiments were designed to determine the presence of rhythmicity in locomotory

\footnotetext{
- Contribution No. 996 from the Center for Environmental and Estuarine Studies, University of Maryland, USA.

- Present Address: Department of Biological Sciences, Baltimore County Campus, University of Maryland, USA.
}

response of the pelagic larva of the brachyuran crab Callinectes sapidus Rathbun. The results are discussed in the context of vertical distribution and consequent dispersal of the larvae.

\section{MATERIALS AND METHODS}

Ovigerous Callinectes sapidus were obtained from lower Chesapeake Bay and returned to the laboratory with egg mass intact. Eggs were then separated from the egg mass, transferred to $25 \mathrm{ml}$ Erlenmeyer flasks containing seawater at $30 \mathrm{ppt}$ salinity, and agitated until hatching on a reciprocating shaker at $110 \mathrm{rpm}$. Room temperature was approximately $22^{\circ} \mathrm{C}$; ambient light approximated 12:12 LD. Upon hatching, the larvae were placed in shallow culture bowls measuring $10 \mathrm{~cm}$ in diameter. Each bowl contained approximately 200 larvae in $100 \mathrm{ml}$ of filtered seawater. Larvae were fed the rotifer Brachionus plicatilis Muller ad libidum (Sulkin and Epifanio, 1975; Sulkin, 1975b, 1978). Larvae were transferred daily to new bowls of fresh seawater and fed. Cultures were maintained at $21^{\circ}-23^{\circ} \mathrm{C}$.

Larvae from three different crabs (designated as 104, 105 and 107) were used in the present experiments. From each of the three crabs, four culture groups were established (designated as A, B, C, and D). Larvae in all groups were subjected to $12: 12 \mathrm{LD}$ regimes for the first $48 \mathrm{~h}$ after hatching. The light period extended from 0800 to 2000 ; the dark from 2000 to 0800 the following day. After the $48 \mathrm{~h}$ entrainment period, the groups were set up in the experimental light regimes indicated in Table 1. 
Table 1. Callinectes sapidus. Light regimes to which various experimental groups were subjected during the course of the experiments (LD: $12 \mathrm{~h}$ light, $12 \mathrm{~h}$ dark; LL: $24 \mathrm{~h}$ light)

\begin{tabular}{|cccc|}
\hline Group number & \multicolumn{3}{l}{ Light regime } \\
& $\begin{array}{c}\text { Initial } \\
\text { entrainment } \\
\text { period }\end{array}$ & $\begin{array}{c}\text { Experimental period } \\
0-48 \mathrm{~h}\end{array}$ & $48-96 \mathrm{~h}$ \\
\hline $104 \mathrm{~A}$ & LD & LD & - \\
B & LD & LD & - \\
C & LD & LL & - \\
D & LD & LL & - \\
105 A & LD & LD & - \\
B & LD & LD & - \\
C & LD & LI & - \\
D & LD & LL & - \\
107 A & LD & LD & LD \\
B & LD & LD & LL \\
C & LD & LL & LD \\
D & LD & LL & LL \\
\hline
\end{tabular}

At $6 \mathrm{~h}$ intervals larvae were removed from each group at random and were placed in a rectangular Plexiglas chamber, $30 \mathrm{~cm}$ long, $3.3 \mathrm{~cm}$ wide, and 2.7 $\mathrm{cm}$ high. The larvae were attracted to one end of the chamber by a white light aimed down the axis of the chamber (intensity $7.5 \mathrm{Wm}^{-2}$ at proximal end). Larvae were induced to swim along the axis of the chamber by reversing the direction of the light. Individual larvae were timed as they traversed a $5 \mathrm{~cm}$ long interval marked off in the middle of the chamber. The swim rates of 10 larvae, randomly selected, were measured at each interval for each group. Data were converted to $\mathrm{cm} \sec ^{-1}$ values and plotted as means. The low frequency of measurement in these experiments did not permit periodogram analysis of the data. Swim rate was used as the diagnostic parameter of locomotory response because it can be rigorously measured. The horizontal orientation of the experimental chamber eliminated the complicating factors of gravity response and passive sinking.

The use of light as an orienting stimulus is a potentially complicating factor in these experiments. Only those individuals moving towards the light were used, thus eliminating potential bias imposed by possible rhythmic variation in phototactic response.

\section{RESULTS}

Figure 1 shows the results for five independent groups that were maintained on the 12:12 LD light regime throughout the experiment. These five trials were conducted over several weeks and occurred under a variety of lunar, tidal, and weather conditions. Experiments commenced at 0800 . Although the fre-

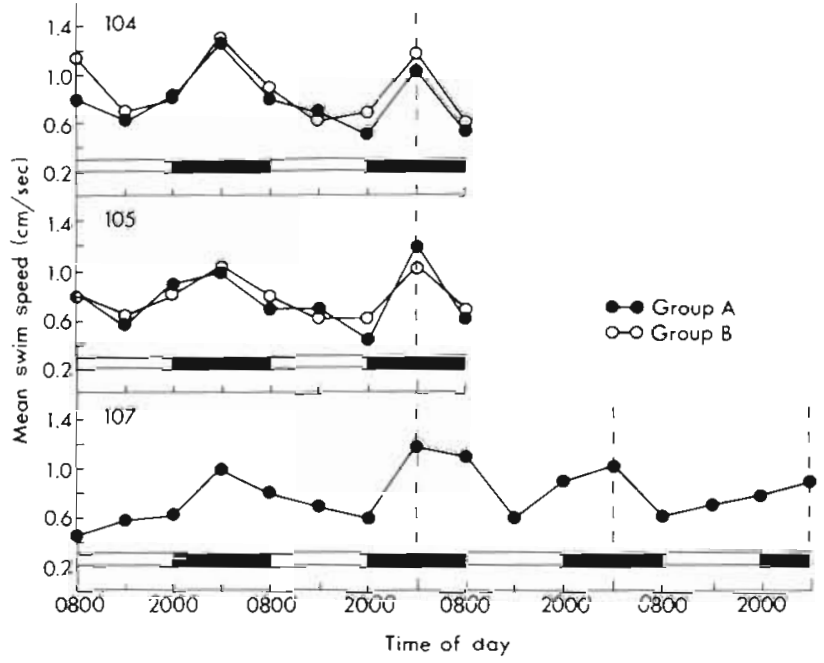

Fig. 1. Callinectes sapidus. Mean swimming speed as a function of time of day for two groups of larvae from each of three different crabs $(104,105,107)$ entrained in alternating periods of light and dark. The periods of light and dark are as indicated. Each data point is the mean of 10 independent measurements

quency of measurement was not sufficient to apply periodogram analysis, each experimental group was subjected to one-way analysis-of-variance to determine whether there was significant difference among the means. As shown in Table 2, significant difference was found in each of the five replications. Perusal of the mean swimming speeds shows that in all five trials, peak readings occurred at consecutive 0200 readings. In trial 107-A, which was extended for $90 \mathrm{~h}$, peak values occurred at three consecutive 0200 readings. Because the experiment was terminated at the fourth 0200 reading it is impossible to determine whether the value represents a peak. The reduction in value at 0800 , even though the larvae were maintained in the dark between 0200 and 0800 , suggests that the 0200 peak value was not merely a 'dark adaptation' response, but a component of a locomotory rhythm.

Figure 2 shows the results for five independent groups which were transferred to a constant light con-

Table 2. Callinectes sapidus. Results of one-way analysis-ofvariance on the means for each of the five repetitions maintained on the 12:12 LD cycle. Degrees of freedom are shown for each $F$-value in parentheses

\begin{tabular}{|ccc|}
\hline $\begin{array}{c}\text { Experimental } \\
\text { groups }\end{array}$ & F-Value & Probability \\
\hline $104 \mathrm{~A}$ & $5.31(8,81)$ & $<0.001$ \\
$104 \mathrm{~B}$ & $4.38(8,81)$ & $<0.001$ \\
$105 \mathrm{~A}$ & $6.42(8,81)$ & $<0.001$ \\
$105 \mathrm{~B}$ & $3.03(8,81)$ & $<0.005$ \\
$107 \mathrm{~A}$ & $5.31(15,144)$ & $<0.001$ \\
\hline
\end{tabular}


dition (LL) immediately after the initial $48 \mathrm{~h}$ entrainment period. Note that although there is variation in swim rate and some suggestion of higher values during presumptive dark periods, the clear periodicity seen in Figure 1 is absent. It would appear that continuous entrainment conditions are required to 'set the clock' and maintain the locomotory rhythm.

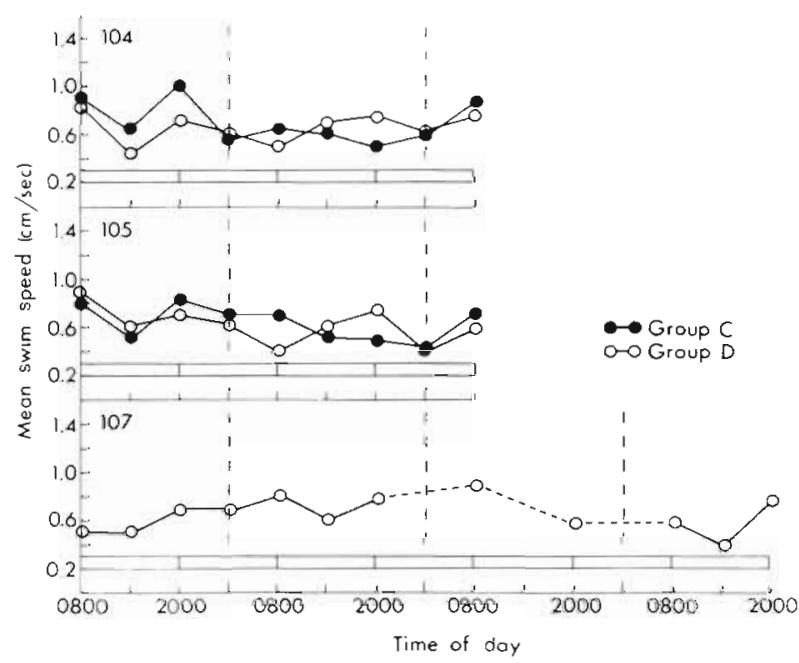

Fig. 2. Callinectes sapidus. Mean swimming speed as a function of time of day for two groups of larvae from each of three different crabs $(104,105,107)$ entrained in constant light. Each data point is the mean of 10 independent measurements

Figure 3 shows the results of two trials (larvae from crab 107 only) where light regimes were further manipulated. In trial 107-B, the LD entrainment light regime was maintained for an additional $48 \mathrm{~h}$. The expected peak values occurred at successive 0200 readings. After the additional $48 \mathrm{~h} \mathrm{LD}$ entrainment period, constant light (LL) was maintained. Although periodicity in response seems to occur, peak values are reset to occur at successive 2000 readings, signalling a shift in phase of the rhythm. In trial $107-\mathrm{C}$, the initial $48 \mathrm{~h}$ LD entrainment period is followed by $48 \mathrm{~h}$ of constant light (LL). As expected (Fig. 2), no clear rhythm is present. After the additional $48 \mathrm{~h}$ of LL, the LD regime was reintroduced. The data suggest establishment of locomotory rhythm, although the rhythm is not perfect. Both results reinforce the conclusion that the rhythm is persistent, but is highly dependent upon light entrainment for synchronization.

\section{DISCUSSION}

The existence of a locomotory rhythm has been demonstrated for a wide variety of terrestrial and aquatic animals. Allen (1972) has reviewed the relevant literature on post-larval decapod crustaceans. Both tidal and circadian locomotor rhythms have been documented for brachyuran crabs (Naylor, 1958, 1963; Barnwell, 1966; Naylor and Williams, 1968; Williams and Naylor, 1967, 1969; Palmer, 1973; Honegger, 1973). These authors have demonstrated a wide variety of rhythm patterns, degree of persistence, apparent 'Zeitgebers', and response to temperature.

The data presented here suggest the presence of a strong diel rhythm in locomotor acitivity, but one with weak persistence in the absence of the light synchronizer. This may be similar to the 'hour-glass' timing mechanism described by Enright and Hamner (1967) for the amphipod Tiron sp. With Tiron sp. dusk triggered upward migration and set up a onecycle timer which resulted in downward migration $12 \mathrm{~h}$ later. In the present case, the light-dark cycle triggers an increase in swim rate, which is reversed within $12 \mathrm{~h}$.

In the present experiments, frequency of measurement was not sufficient to apply periodogram analysis or to describe the rhythm more precisely. Neither are

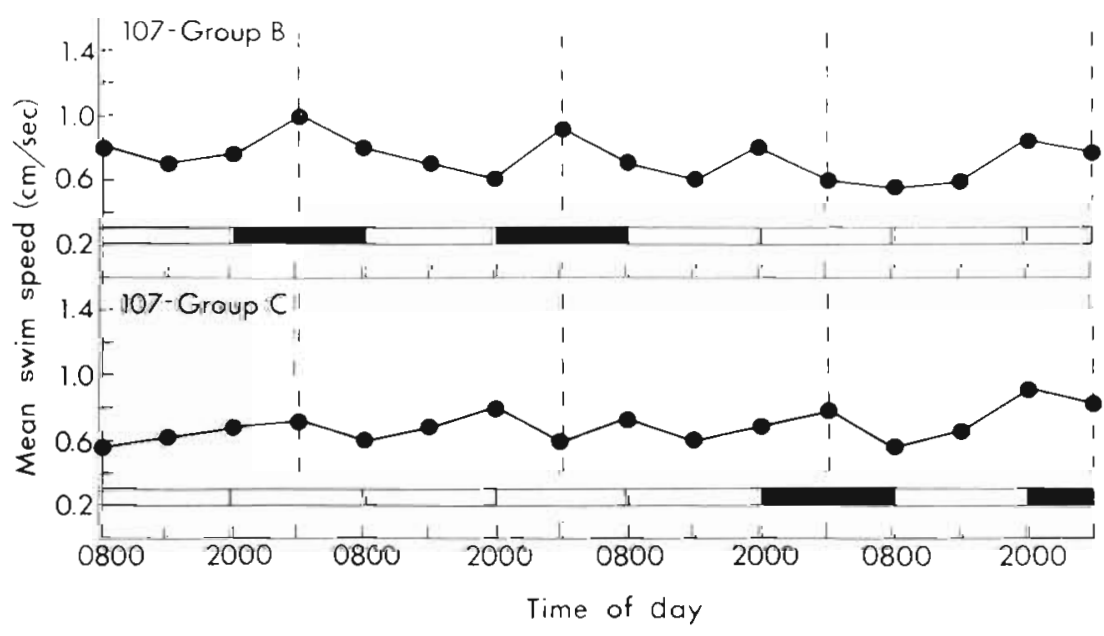

Fig. 3. Callinectes sapidus. Mean swimming speed as a function of time of day for groups of larvae entrained as indicated. Periods of light and dark are as indicated. Each data point is the mean of 10 independent measurements 
we able to eliminate completely the possibility that tidal or other rhythms may be complicating what appears to be a clear diel rhythm. Both deCoursey (1976) and Cronin and Forward (1979) have described tidal rhythms in larvae of estuarine crab species. Nevertheless, the identical nature of the response seen in group replicates and among groups taken from different crabs at different dates suggests strongly the presence of a diel rhythrn.

The significance of the reported locomotory rhythm to vertical movement must be evaluated in relation to the other factors which govern vertical distribution.

Movement to surface waters during the early part of larval development has been reported for a variety of benthic invertebrates (e.g. Hyman, 1925; Russell, 1927; Thorson, 1946; Carriker, 1951; Bousfield, 1955; Bayne, 1964). Sulkin (1973) asserted that such movement was an adaptation which enhanced dispersal by subjecting the larvae to a variety of horizontally moving currents. Other authors have suggested that surface waters provide food, warmth, illumination, and respite from direct competition with benthic adults (Thorson, 1946; Mileikovsky, 1972).

A variety of behavioral adaptations may produce upward movement in early stages. In the two xanthid crabs.Leptodius floridanus (Gibbes) and Panopeus herbstii Milne-Edwards, upward movement of the first zoeal stage is the result of positive phototaxis and negative geotaxis (Sulkin, 1973, 1975a). In combination with these taxis responses, high barokinesis serves as a depth regulatory device by increasing swim rate as the larvae sink (Sulkin, 1973).

In Callinectes sapidus, the first zoeal stage has been reported to be positively phototactic (Forward, 1977; Sulkin and van Heukelem, unpublished). We have found the first zoeal stage to exhibit negative geotaxis (unpublished). Thus both photo- and geo-taxis responses would position the larvae such that active swimming would result in upward movement.

If one assumes that light enhances upward movement either by insuring the appropriate primary orientation or by stimulating high photokinesis, the observed locomotory rhythm may be a depth regulatory mechanism. In negatively geotactic larvae, increased swim rate during early morning hours may compensate for the absence of light. Alternatively, the rhythm could provide a mechanism for diurnal vertical migration, effecting a net upward movement during the night and a net downward movement commencing prior to dawn.

The choice between the alternatives depends upon the rate values of many contributing factors, including intrinsic swim rate, sink rate, and per cent time spent actively swimming during the day and night. These factors are presently under investigation.
Acknowledgements. The authors wish to thank Ms. Kathy Kiorpes and Mr. Dan Levine for their technical assistance. The research was supported in part by the Maryland Sea Grant program (Project R/F-8).

\section{LITERATURE CITED}

Allen, J. A. (1972). Recent studies on the rhythms of postlarval decapod crustacea. Oceanogr. mar. Biol. A. Rev., 10, $415-436$.

Barnwell, F. H. (1966). Daily and tidal patterns of activity in individual fiddler crabs (genus Uca) from the Woods Hole region. Biol. Bull. mar. biol. Lab., Woods Hole, 130, 1-17.

Bayne, B. L. (1964). The response of the larvae of Mytilus edulis to light and to gravity. Oikos, 15, 162-174.

Bousfield, E. L. (1955). Ecological control of the occurrence of barnacles in the Miramichi estuary. National Museum of Canada, Bulletin No. 137, 1-69.

Carriker, M. R. (1951). Distribution of oyster larvae in New Jersey estuaries. Ecol. Monogr., 21, 17-38.

Cronin, T. W. and Forward, R. B., Jr. (1979). Tidal vertical migration: an endogenous rhythm in estuarine crab larvae. Science, N.Y., 205, 1020-1022.

DeCoursey, P. J. (1976). Vertical migration of larval Uca in a shallow estuary. Am. Zool, 16, 244.

Enright, J. T. and Hamner, W. M. (1967). Vertical diurnal migration and endogenous rhythmicity. Science, N.Y., 157, $937-941$

Enright, J. T. (1975). Orientation in time: endogenous clocks. In O. Kinne (Ed.), Marine Ecology, Vol. II, Physiological Mechanisms, Part 2. Wiley, London. pp. 917-944.

Fincham, A. A. (1970). Rhythmic behavior of the intertidal amphipod Bathyporeia pelagica. J. mar. biol. Ass. U.K., 50, $1057-1068$.

Forward, R. B., Jr. (1977). Occurrence of a shadow response among brachyuran larvae. Mar. Biol., 39, 331-341.

Hindley, J. P. R. (1974). Effects of endogenous and some exogenous factors on the activity of the juvenile banana prawn Penaeus merquiensis. Mar. Biol., 29, 1-8.

Honegger, H. W. (1973). Rhythmic motor activity responses of the California fiddler crab $U c a$ crenata to artificial light conditions. Mar. Biol., 18, 19-31.

Hughes, D. A. (1969a). Responses to salinity change as a tidal transport mechanism of pink shrimp Penaeus duorarum. Biol. Bull. mar. biol. Lab., Woods Hole, 136, 43-53.

Hughes, D. A. (1969b). Evidence for the endogenous control of swimming in pink shrimp Penaeus duorarum. Biol. Bull. mar. biol. Lab., Woods Hole, 136, 398-404.

Hughes, D. A. (1972). On the endogenous control of tide associated displacements of pink shrimp, Penaeus duorarum Burkenroad. Biol. Bull. mar. biol. Lab., Woods Hole, $142,271-280$.

Hyman, D. W. (1925). Studies on the larvae of crabs of the Family Xanthidae. Proc. U.S. natn. Mus., 67, 1-22.

Jones, D. A. and Naylor, E. (1970). The swimming rhythm of the sand beach isopod, Eurydice pulchra. J. exp. mar. Biol. Ecol., 4, 188-199.

Mileikovsky, S. A. (1972). The 'pelagic larvaton' and its role in the biology of the world ocean, with special reference to pelagic larvae of marine invertebrates. Mar. Biol., 16. 13-21.

Naylor, E. (1958). Tidal and diurnal rhythms of locomotor activity in Carcinus maenas. $J$. exp. Biol., 35, 602-610.

Naylor, E. (1963). Temperature relationships of the locomotor rhythms of Carcinus. J. exp. Biol. 40, 669-679. 
Naylor, E. and Williams, B. G. (1968). Effects of eyestalk removal on rhythmic locomotor activity in Carcinus. $J$. exp. Biol., 49, 107-116.

Palmer, J. D. (1973). Tidal rhythms: the clock control of the rhythmic physiology of marine organisms. Biol. Rev, 48 , $377-418$

Russell, F. S. (1927). The vertical distribution of p'ankton in the sea. Biol. Rev., 2, 213-262.

Sulkin, S. D. (1973). Depth regulation of crab larvae in the absence of light. J. exp. mar. Biol. Ecol., 13, 73-82.

Sulkin, S. D. (1975a). The influence of light in the depth regulation of crab larvae. Biol. Bull. mar. biol. Lab., Woods Hole, 148, 333-343.

Sulkin, S. D. (1975b). The significance of diet in the growth and development of larvae of the blue crab, Callinectes sapidus Rathbun, under laboratory conditions. J. exp. mar. Biol. Ecol., 20, 119-135.

Sulkin, S. D. (1978). Nutritional requirements during larval development of the portunid crab, Callinectes sapidus Rathbun. J. exp. mar. Biol. Ecol., 34, 29-41.
Sulkin, S. D. and Epifanio, C. E. (1975). Comparison of rotifers and other diets for rearing early larvae of the blue crab, Callinectes sapidus Rathbun. Estuar. \& Coast. Mar. Sci., 3, 109-113.

Thorson, G. (1946). Reproduction and larval development of Danish marine bottom invertebrates. Medd Kommn Danm. Fisk.-og Havunders (ser. Plankton), 4, 1-523.

Thorson, G. (1964). Light as an ecological factor in the dispersal and settlement of larvae of marine bottom invertebrates. Ophelia, 1, 167-208.

Williams, B. G. and Naylor, E. (1967). Spontaneously induced rhythm of tidal periodicity in laboratory-reared Carcinus. J. exp. Biol., 47, 229-234.

Williams, B. G. and Naylor, E. (1969). Synchronization of the locomotor tidal rhythm of Carcinus. J. exp. Biol., 51, 715-725.

Wood, L. and Hargis, W. J., Jr. (1971). Transport of bivalve larvae in a tidal estuary. In D. J. Crisp (Ed.), Fourth European Marine Biology Symposium. University Press, Cambridge. pp. 29-44. 